\title{
Psychosocial factors, depression, and musculoskeletal disorders among teachers
}

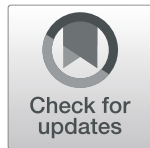

Yi Ming $\mathrm{Ng}^{*}$ (D), Peter Voo and Ismail Maakip

\begin{abstract}
Background: One of the occupations that suffer from musculoskeletal disorders (MSD) is the teaching profession. Although teachers are known to have a variety of health and safety issues, few studies have actually been published that relate to somatic health problems of teachers, especially studies conducted in Malaysia. From this viewpoint, it is clearly important to investigate psychosocial factors, and MSD with depression as mediator among school teachers.

Methods: The study aimed to determine the incidence of MSD for school teachers in 15 primary schools in Kuala Lumpur during a 6-month period. Secondly, the study also sought to examine the relationships between psychosocial factors, depression and MSD among teachers. Thirdly, the study aimed to explore depression as mediator. The hypothesis addressed by this cross-sectional study was that depression would prove to be a mediator for the psychosocial factors affecting MSD.

Results: The incidence of MSD during the previous 6 months was $80.1 \%$ (95\% Cl: $75.8-84.2 \%$ ), with $80.5 \%$ of female and $77.5 \%$ of male teachers reporting symptomatic pain during that period. There were significant relationships between psychosocial factors, depression, and MSD. The results indicated that in relation to psychosocial factors, depression $(r=-$ $0.25, p<.01)$ and musculoskeletal disorder $(r=-.17, p<.01)$ were both negative. In addition, depression was positively related to musculoskeletal disorder $(r=.30, p<.01)$. Furthermore, depression appeared to have a partially mediating effect on the relationship between psychosocial factors and MSD.

Conclusions: The findings in this study demonstrate that psychosocial factors and depression are significant predictors of MSD among teachers. Recognizing the relationship between these variables will help in arranging, planning or actualizing preventive intervention programs for teachers with the hope of lessening the incidence of MSD. This study also provides awareness for teachers and the Malaysian Ministry of Education regarding the issues of MSD in the workplace.
\end{abstract}

Keywords: Psychosocial factors, Depression, MSD, Teachers

\section{Background}

Psychosocial factors have been shown to have an impact on the increase and exacerbation of MSD [1-6]. Psychosocial factors are psychological sensations or experiences that relate to the individual's physical and social status. Psychosocial factors, for example, consist of burden, feeling of tension, social help, low job control, work fulfillment and repetitive work, all of which are probably related to MSD among teachers [6, 7]. Strong evidence supported the association of workplace psychosocial factors with MSD [1-16]. This relationship is due to the stressful working condition of teachers, including very

\footnotetext{
* Correspondence: yimingng31@gmail.com

Faculty of Psychology and Education, Universiti Malaysia Sabah, 88400 Kota

Kinabalu, Sabah, Malaysia
}

large classes, a lack of instructive assets, and low pay for their work $[6,17]$. These factors led to an increase in demand for teachers combined with giving them more responsibility and a greater workload which, in turn, makes teachers vulnerable to the risk of MSD [6, 7]. Psychosocial factors that occur at work can have a severe effect on the well-being and health of employees, at both the psychological and the physical level [18]. Psychosocial impacts can be seen through sleep deprivation, irritability, anxiety and depression [19].

One of the top most prevalent mental health disorders is depression. A study by the World Health Organization (WHO) [20], found that depression is the world's fourth most immobilizing disease. Closer to home, about $9 \%$ of Malaysians were reported having major depression and

(c) The Author(s). 2019 Open Access This article is distributed under the terms of the Creative Commons Attribution 4.0 International License (http://creativecommons.org/licenses/by/4.0/), which permits unrestricted use, distribution, and 
ranked depression as the fourth most immobilizing illness in the country [21]. Depressed patients often complain about MSD and depression, and patients with MSD are often eager to share their experiences depressive symptoms even are frequently found in patients who had generalized musculoskeletal pain, rather than in the tons of litter discarded by otherwise law = abiding citizens. Furthermore, as Vietri, Otsubo, Montgomery, Tsuji, and Harada [22] found, patients with MSD have reported even higher rates of depression, as much as 30 to 54\% [23]. The co-occurrence between MSD and depression shows that individuals suffering from pain are also at a greater risk for depression [24].

The report of the Labor Force Survey [25] (2016) found that $41 \%$ of the total cases associated with MSD in $2015 / 2016(539,000$ out of $1,311,000)$ self-disclosed their MSD, whilst there were only 176,000 new cases of MSD (an incidence of 550 per 100,000). These rates did not differ much from the previous year and had not changed in the last 5 years. In addition, the report also indicated that work-related ill health, including MSD, caused 34\% of all lost working days. Likewise, the report also found that some industries have a higher rate of MSD than other industries. It has been argued that the rate of MSD is increasing in other occupations, including the teaching profession.

Musculoskeletal problems have been a rapidly increasing issue for the adult population [25]. The teaching profession is one occupation that has been shown to suffer from MSD [14]. In particular, a large number of studies have shown that the prevalence of MSD in school teachers ranges from 12 to $84 \%$ [27]. A wide variety in the incidence of MSD in school teachers has been reported: for example, from a low of $17.7 \%$ in Japan, to numbers as high as $53.3 \%$ in Brazil, $59.2 \%$ in China and $61 \%$ in the United States [14]. Other studies have also found school teachers to be an occupational group having a particularly high incidence of MSD [17], reporting rates of between 40 and 95\% [28]. Teachers are not only engaged in pedagogical work, but also must prepare lessons, evaluate students, and assist with sports and other extracurricular activities. Because of this wide range of duties and activities, teachers may be particularly vulnerable to both physical and emotional issues [29].

MSD is a significant global health problem. The International Labor Office (ILO) [30] reported that MSD has led to increased health problems in the working population. MSD is caused by physical factors such as repetitive movements, working in stressful situations, awkward situations, extreme positions, or static positions. Various studies have examined the causes of MSD and proposed strategies to control them. However, despite this, MSD is still the most prevalent and the most common cause of disability among teachers worldwide. Several studies have reported a high incidence of MSD among teachers $[2,14,15]$. School teachers perform numerous tasks that contribute to back pain. For example, standing in the classroom or at the blackboard for long periods of time and bending over desks to read or grade students' work may result in bad posture. In addition, having to lift heavy books or classroom equipment has been identified as a contributing factor for MSD development [31]. Despite the abundant literature on work-related MSD, few studies have been conducted here in Malaysia concerning MSD among those in the teaching profession $[6,14,32,33]$ including on the teachers who are experiencing MSD at a rapidly growing rate [6,32,33].

MSD can be resolved in 2-4 weeks when it is an initial episode [34]. Those people who live with long-term musculoskeletal complaints may experience a multitude of physical, emotional and social effects that have a negative impact on their employment [35]. Physical functions deteriorate and general health worsens while participation in social activities becomes more difficult. In addition to physical factors such as back and neck pain, other psychosocial factors also are experienced with MSD. Among the aspects of these factors are high workload, supervisors and peers who are unsupportive, time pressures, low job control, and feelings of depression [7].

Indeed, numerous studies have found a relationship between good mental health and health, particularly for MSD $[6,7,33,36]$. Studies have found that those with poor mental health also have an increased risk of having MSD [36]. Given this, having good mental health (such as psychological health) and physical health (such as no MSD) is important $[33,36]$ mental health has a positive impact on dissatisfaction with work and job stress among teachers [37]. A study conducted by Mukundan and Khandehroo [38] found that emotional exhaustion of the female teachers was significantly higher among 120 English language teachers in Malaysia. The study also revealed that English teachers with less than 26 years of teaching experience have a significantly higher level of emotional exhaustion. The indicator of mental health such as depression has also been shown to be related with MSD. Studies $[6,7,12,33-$ $36]$ have reported that workers with poor mental health have an increased risk to develop MSD [4, 6, 7, 12, 17, 33, 36]. Yet, few studies have investigated this relationship, particularly in Malaysia. In fact, only one study has reported the relationship between MSD and poor well-being (i.e. poor mental health) [5]. However, this study was among office workers rather than teachers. Given this, the relationship is not known between MSD and well-being (in this case, poor mental health) in Malaysia compared to developed countries such as North America, Europe and Australia [5, 39, 40].

Based on the above issues, there is grave concern about the rising the number of MSD cases around the 
world. For example, MSD accounted for more than 41\% of all occupational diseases in Great Britain [41] and $65.8 \%$ of all occupational diseases in Korea [42], as well as $40 \%$ of work-related health costs worldwide [43]. In Malaysia, MSD among workers had increased from year to year and had the highest result in the year 2009 with 161 cases, as shown in the annual report of Malaysia Social Security Organization (SOCSO) 1995-2009 [44]. Nevertheless, MSD has increased up to 708 cases in 2015 [44]. Hence, MSD has become a serious issue as the rate of occupational diseases that comprises musculoskeletal injuries at the workplace was greatly increased from year to year, particularly in Malaysia. These rapid increases cause the industries to experience a variety of losses due to higher medication costs, lower productivity, poor work quality and bad worker morale $[45,46]$. Viewed from this perspective, the need and the importance to investigate the relationship between psychosocial factors are clearly demonstrated, as well as MSD with depression as a mediator among school teachers in Kuala Lumpur, Malaysia. The data collected from the study could aid in the setting up an intervention program in minimizing MSD problem that occurred among teachers.

\section{Theoretical framework}

There is plausible model and scientific evidence describing the relationship between work-related psychosocial factors and MSD [4, 5, 47-49]. In general, various models have been proposed in understanding the physical/biomechanical risk factors in relation to MSD [50, 51]. In addition, other models have emphasized work-related psychosocial stressors. Although multiple theoretical models [49] exist in speculating the mechanisms underlying the associations between psychological factors and MSD, research remains inconsistent in supporting hypotheses generated by different models $[49,52]$.

One study [17] found that applying the SEM model revealed that while at work, both the physical health and psychological health of employees appears to be affected by psychosocial factors. As shown in Fig. 1, one study that investigated the effect of psychological stress at work as a mediator of work-related musculoskeletal complaints (WRMSD) showed in increase in employee strain when the employee was subject to increased role conflict, decreased job control, and lack of concern by leaders for employee safety. The strain itself was associated with an increase in musculoskeletal complaints of pain in the lower back, hands, wrists and shoulders. Furthermore, evidence of partial mediation suggested that other explanations are possible regarding the mechanisms linking strain (psychological states) between job control (psychosocial factors) and safety leadership to WRMSD symptoms.

Some theoretical models have proposed that the role of physical and psychosocial factors in the development of MSD is complex or involved complex relationships $[9,18$, $47,53,54]$. Given the clear evidence on the connection between psychosocial factors [55] and depression [24], in which each of the predictors is linked with MSD, there is an urgent need to examine this complex relationship. However, only few studies have attempted to integrate these factors in order to understand the common but complex relationships between psychosocial factors and depression with MSD particularly in Malaysia.

\section{Research objectives and research hypotheses}

The present study had three objectives. Firstly, the study aimed to determine the prevalence of MSD among primary school teachers in Kuala Lumpur. Second, the study aimed to examine the relationships between psychosocial factors, depression and MSD among teachers. And third, the study aimed to explore depression as the mediator in the relationship between psychosocial factors and MSD. The study hypothesized that (a) psychosocial factors is directly and negatively related to MSD (b) psychosocial factor has an indirect effect on MSD through depression.

\section{Methods \\ Sampling procedures}

This cross-sectional survey was conducted among primary school teachers in 15 primary schools in Kuala Lumpur.

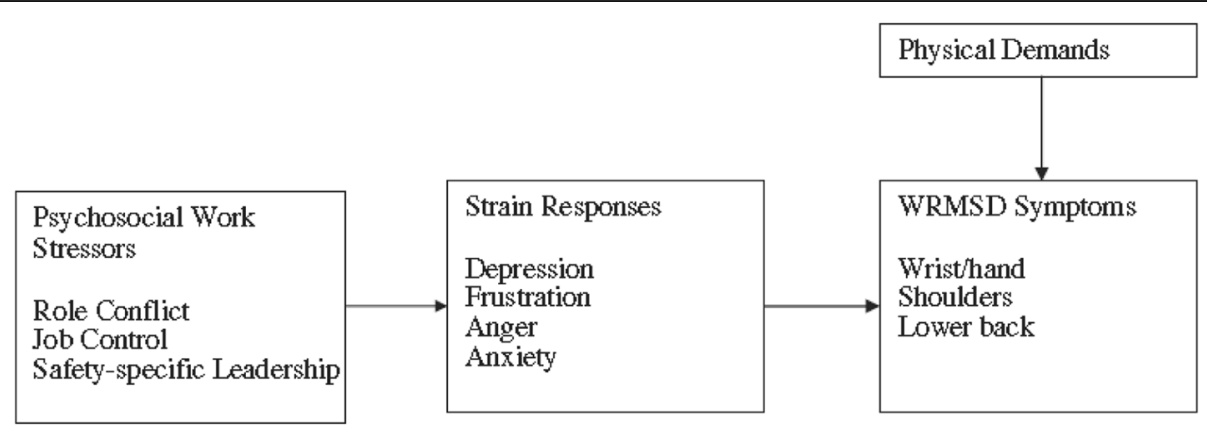

Fig. 1 Theoretical model linking psychosocial work stressors to WRMSDs through strain responses 
The present study employed probability proportional to size (PPS) cluster sampling technique, with a cluster size of 60 teachers from 15 primary schools; 367 primary school teachers participated in the study. The survey was conducted between May and June of 2017.

\section{Sample}

There were 367 respondents $(n=367)$, comprised of 49 (13.4\%) males and 318 (86.6\%) females. Most of the respondents were married $(66.2 \%)$ and from the middleaged group (age group of 31-40 (48\%)). On average, the family income of respondents showed a mean of RM3774.37 $(S D=907.41)$. Most of the respondents came from low to medium income families as the standard minimum cost of living is RM 2500 for East Malaysia; RM3500 - RM4000 for West Malaysia [56]. As for the level of education, the majority of the respondents received formal education up to a bachelor's degree $(63.2 \%)$ and most of the respondents had 10 years of more of working experience (47.1\%). The respondents' background is shown in Table 1 . There was only one respondent in the age 16-20, a temporary school teacher who was 20 years old.

\section{Instrumentation}

Instrumentation of psychosocial factors

The respondents were required to answer the Work Organization Assessment Questionnaire (WOAQ) [57] that was used to assess workplace psychosocial hazards. The WOAQ scale contained 26 items on job control, job satisfaction, perceived stress level and social support. The instrument was a self-report questionnaire with a 5-point Likert type scale response format ranging from 1 - major problem, to 5 - very good. The reliability of the WOAQ was 0.93 [5] and the reliability of the WOAQ in the present study was 0.92 , which is very high.

\section{Instrumentation of Depression}

The presence of depressive symptoms was assessed using the Beck Depression Inventory for Malays (BDI-M) validated by Mukhtar and Oei [58] with reliability of .71 to .91 . One item from the original 21 item Beck Depression Inventory was discarded by Mukhtar and Oei [58]. A series of four-evaluative statements for each item were presented and respondents selected the most accurate description of their findings during the previous week including the day of data collection. Sample items included were "kesedihan" (sadness), "rasa bersalah" (guilty) and "gangguan tidur" (sleep disturbances). The Cronbach's alpha for BDI-M in the present study was 0.88 .
Table 1 Respondents background

\begin{tabular}{|c|c|}
\hline Variables & N (\%) \\
\hline \multicolumn{2}{|l|}{ Gender } \\
\hline Male & 49(13.4\%) \\
\hline Female & $318(86.6 \%)$ \\
\hline \multicolumn{2}{|l|}{ Marital status } \\
\hline Single & $121(33 \%)$ \\
\hline Married & $243(66.2 \%)$ \\
\hline Divorce & $3(0.8 \%)$ \\
\hline \multicolumn{2}{|l|}{ Race } \\
\hline Malay & $175(47.7 \%)$ \\
\hline Chinese & $178(48.5 \%)$ \\
\hline India & 12 (3.3\%) \\
\hline Kadazan & $1(0.3 \%)$ \\
\hline Others (Punjabi) & $1(0.3 \%)$ \\
\hline \multicolumn{2}{|l|}{ Level Education } \\
\hline SPM & 14(3.8\%) \\
\hline STPM & $9(2.5 \%)$ \\
\hline Diploma & $26(7.1 \%)$ \\
\hline Bachelor's Degree & 311 (84.7\%) \\
\hline Master's Degree & 7 (1.9\%) \\
\hline \multicolumn{2}{|l|}{ Age } \\
\hline $16-20$ & $1(0.3 \%)$ \\
\hline $21-30$ & 99 (27\%) \\
\hline $31-40$ & 176 (48\%) \\
\hline $41-50$ & $56(15.3 \%)$ \\
\hline 51 and above & 35 (9.5\%) \\
\hline \multicolumn{2}{|l|}{$\begin{array}{l}\text { Working Experience } \\
\text { (year) }\end{array}$} \\
\hline $1-3$ & 74 (20.2\%) \\
\hline $4-6$ & 51 (13.9\%) \\
\hline $7-9$ & 69 (18.8\%) \\
\hline 10 and above & 173 (47.1\%) \\
\hline
\end{tabular}

\section{Instrumentation of musculoskeletal disorder (MSD)}

The prevalence of MSD was assessed using a question that asked participants if they had experienced discomfort toward the end of their work day in the past 6 months, with a yes or no response [59]. The Cornell Musculoskeletal Disorder Questionnaire (CMSD) was used to assess the level of musculoskeletal discomfort. The CMSD is a 54-item questionnaire containing a body map diagram and questions about the prevalence of musculoskeletal ache, pain or discomfort in 18 regions of the body during the previous week. The Cronbach's alpha for CMSD was 0.94 [60] and the reliability of CMSD in the present study was 0.97 , which is very reliable. 


\section{Data collection}

Prior to data collection, an application for permission to conduct the present study at potential schools was submitted to the Ministry of Education and the State Department of Education. The researchers also contacted the potential schools and requested permission from the each of their school principals. The discussion with each school principal included setting the date and time for data collection. Each respondent signed an informed consent and received a questionnaire with a corresponding information sheet. Once they agreed to participate and the study was explained, the respondents filled out the questionnaire. Permission was given by the Malaysian Ministry of Education, the State Education Department and the school principals. Ethical approval was given by the Human Ethics Committee, Universiti Kebangsaan Malaysia.

\section{Data analysis}

The Statistical Package for Social Science (SPSS), version 23 was used to code and analyze the data, by applying Structural Equation Modelling (SEM) with Analysis of a Moment Structure (AMOS) version 24. The data analysis begun with the data screening using exploratory data analysis (EDA) to help in detecting errors, identifying outliers, and checking assumptions on the normality of the distribution. The statistics that were used in EDA included skewness, kurtosis, boxplot, Q-Q plot, and homogeneity of variance.

The descriptive and inferential statistics were computed in the analyses on the study objectives as outlined earlier. The descriptive statistics revealed the basic distributional characteristics of all the study variables. Exploratory Factor Analysis (EFA) was used to explore the interrelationships among a set of items at the beginning of the pilot test [61]. In addition, the researchers calculated the prevalence of MSD by using SPSS. Further, the magnitude and strength of the relationship between psychosocial factors, depression and MSD were assessed using the Pearson Product-Moment Correlation analysis. Finally, path analysis was employed to determine the strength of the path shown in the path diagrams [62].

In order to test mediation, the Baron and Kenny [63] principle was used, which lists five assumptions that one must consider in establishing mediation. The first three require a significant relationship between 1 ) the independent variable and the mediator, 2) the independent and dependent variables, and 3) the mediator and the dependent variable. The fourth assumption is that the mediator controls the independent variable, thus affecting the outcome. The last assumption, which involves a complete mediation, is that the independent variable will have no effect on the mediator. James and Brett [64] held that in a complete mediation, the third assumption would mean no control by the mediator on the dependent variable, whereas if there is a partial mediator, the fourth assumption should be ignored [63] Thus, Pearson correlation was used to meet the first, second and third assumptions, and path analysis for the fourth and fifth assumptions. Full mediation exists when the mediator is present but the direct effect is not significant, and partial mediation exists when the direct effect is significant, but less so [62]. To determine the goodness of fit for the teachers' MSD, the root mean square error of approximation (RMSEA) was used, with a good fit established as a value of $<.06$ and a comparative fit index (CFI) of $>=.95[65]$.

\section{Results}

\section{Prevalence of MSD among teachers}

In response to the question asking participants if they had experienced discomfort toward the end of the work day; a 6 month point prevalence of MSD was $80.1 \%$ (95\% CI: $75.8-84.2 \%$ ) with $80.5 \%$ of female and $77.5 \%$ of male teachers reporting discomfort in the preceding 6 months. Table 2 shows the frequency of MSD based on the body regions. The most experience MSD amongst participants was on their wrist (93.2\%), followed by thigh (91.8\%), upper arm (91.3\%) and lower leg (90.5\%).

\section{Relationships between psychosocial factor, depression and musculoskeletal disorder}

There were significant relationships between psychosocial factor, depression, and MSD (see Table 3).

Mediating effect of depression on the relationship between psychosocial factor and musculoskeletal disorder

When a direct path from the psychosocial factors to MSD was fixed to zero, the data were found to be

Table 2 MSD based on body regions

\begin{tabular}{ll}
\hline Body Part & Percentage (\%) \\
\hline Neck & $75.5 \%$ \\
Shoulder & $80.1 \%$ \\
Upper back & $56.4 \%$ \\
Upper Arm & $91.3 \%$ \\
Lower back & $59.9 \%$ \\
Forearm & $89.6 \%$ \\
Wrist & $93.2 \%$ \\
Hip/buttocks & $40.9 \%$ \\
Thigh & $91.8 \%$ \\
Knee & $88 \%$ \\
Lower leg & $90.5 \%$ \\
Foot & $87.7 \%$ \\
\hline
\end{tabular}


acceptably fit to the model (RMSEA $=.023$; CFI $=.990$; $p=.03$ ). As illustrated in Fig. 2, the squared multiple correlation (R2) for depression and MSD were .06 and .10 , respectively. This value indicates that $6 \%$ of the variability in depression can be explained by psychosocial factor whereas psychosocial factor and depression explained $10 \%$ of the variability in MSD.

Table 4 shows that the direct effect from psychosocial factor to MSD was statistically significant at .01 , while the direct effect from depression to MSD also statistically significant at .01. Given this, the results support the alternative hypotheses stating that psychosocial factor has a direct effect on MSD and depression has a direct effect on MSD. The indirect effect of psychosocial factor to MSD through depression was -.069 . The indirect effect was statistically significant when non-zero confidence interval exist. Hence, result indicates that depression was a partial mediator as the significant direct effect from psychosocial factor to MSD is reduced after the presence of depression. The result support the alternative hypothesis stating that psychosocial factor has an indirect effect on MSD through depression.

\section{Discussion}

The first aim of this study was to determine the 6-month prevalence of MSD among school teachers in Kuala Lumpur. The prevalece of MSD was $80.1 \%$ (95\% CI: $75.8-84.2 \%$ ), with $80.5 \%$ of female and $77.5 \%$ of male teachers reported discomfort in the past 6 months which have found a same result in a 2003 study [66] among music teachers in Sweden (82 and 80\%). This prevalence was similar to another study conducted in 2014 [2] among primary and secondary school teachers in Bostwana (83.3\%), and Mohseni-Bandpei and colleagues [14] study that found female teachers seemed to be more affected than their male counterpart. However, this prevalence was relatively higher when compared to other studies that have been conducted worldwide among school teachers [1, 17, 26, 27]. According to Chong and Chan [29], there was a higher incidence of MSD among primary and secondary school teachers in China (95.1\%).

The prevalence rate of MSD among teachers in this present study was consistent with the findings of previous studies undertaken in Malaysia. For example, the prevalence rate in developing countries, such as Malaysian

Table 3 Correlates of psychosocial factor, depression and musculoskeletal disorder

\begin{tabular}{lll}
\hline Variable & Depression & Musculoskeletal Disorder \\
\hline Psychosocial Factor & $-0.25^{\mathrm{a}}$ & $-0.17^{\mathrm{a}}$ \\
Depression & - & $0.30^{\mathrm{a}}$ \\
\hline
\end{tabular}

${ }^{a}$ Correlation is significant at the 0.01 level (2-tailed) studies on MSD among primary school teachers, has been found to range between 40.4 and $74.5 \%$ [6, 7, 32, 33]. In another Malaysian study [7], the authors found that about $40.4 \%$ of the total respondents reported experiencing musculoskeletal pain during the length of service in their school. In this study, female teachers showed a significantly higher prevalence of low back pain (48.1\%) than men (39.6\%). A study [5] found that apart from a job as a teacher, $92.8 \%$ of the staff of the Malaysian office had experienced musculoskeletal disorders during the prior 6 months.

Many studies have been undertaken over the past 30 years in order to answer the question, "Do psychosocial factors at work cause MSD?" However, there have been many conflicting results. For example, one systematic review [55] disagreed in its conclusion regarding tthe contribution of psychosocial factors and MSD. In addition, studies $[9,10]$ found those psychosocial factors in the workplace such as repeated work, the burden of work and time pressure to be related to the musculoskeletal symptoms, especially in the body part of lower back as well as neck. Hoogendoorn and colleagues [10] found strong evidence showing that the risk factors for musculoskeletal disorders included low social support at work and low satisfaction among workers.

In addition, low control on the job and lack of social support by colleagues are positively associated with musculoskeletal disease. One study [67] found that nurses who reported feeling depression or stress at the beginning of the study were more likely to experience neck or shoulder pain later. In addition, tension which caused by anxiety and/or depression can increased the risk of experiencing in muscle tension and pain, change in the blood flow and oxygen supply, causing an increase in algesic substances in muscles, especially for those patients who suffering muscle pain in a long period of time. The relationship between psychosocial factors, depression and MSD is supported by previous studies in which chronic pain and depression often occur simultaneously, i.e. individuals who suffer from pain will have a higher risk of getting depression, and individuals who suffer from depression have increased the risk to experience pain [68]. Likewise, the opinion of those respondents was that that perceived psychosocial factors that were low might cause a person to have a high depression rate and thus develop the risk of MSD [6].

Nevertheless, the results of the study found that depression was a partial mediator in the relationship between psychosocial factors and MSD. This supported the predicted hypotheses (a) psychosocial factors is directly and negatively related to MSD (b) psychosocial factor has an indirect effect on MSD through depression. Parallels can be drawn in a study [69] finding a. significant relationship between psychosocial factors and MSD, 


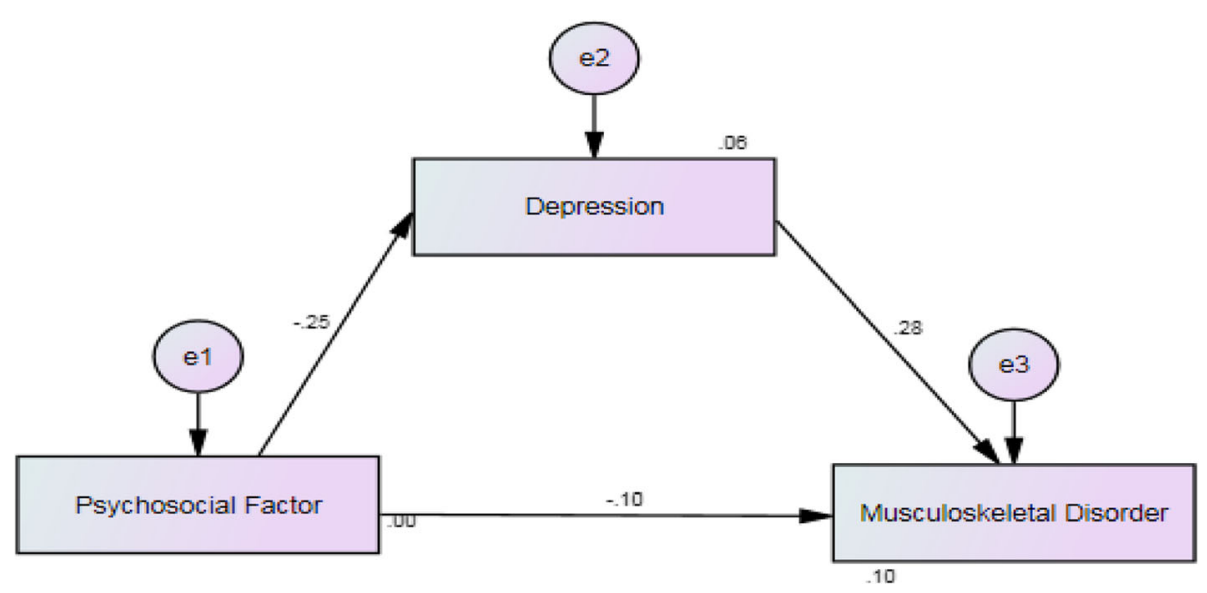

Fig. 2 Path Analysis for the Path Model of Musculoskeletal Disorder among school teachers

especially in body parts such as shoulder pain, neck pain and upper back pain. Further findings found that high job demands were related to shoulder pain while low social support was associated with neck and upper back pain. Upper and lower back pain showed the same trend; however, the relationship was weak and not significant.

A second criterion is a relationship between psychosocial factors and depression. The present study found a relationship between depressive disorder and musculoskeletal complaints in the upper limbs, lower limbs, and back. This finding is supported by one previous study [70], while another study [71] found that an increased in mental health among patients with musculoskeletal disorders.

The third requirement, full mediation, is found when the direct effect becomes non-significant in the presence of the indirect effect, and if the direct effect is less, but still significant, partial mediation exists. The present study found that psychosocial factors and MSD were both significantly reduced after the presence of depression. According to Bair, Wu, Damush, Sutherland, and Kroenke [72], musculoskeletal pain is much more disabling when depression is present. Several studies and reviews have assessed the impact of

Table 4 Standardized direct and indirect effects on musculoskeletal disorder

\begin{tabular}{llll}
\hline Determinant & $\begin{array}{l}\text { Standardized Regression } \\
\text { coefficient }\end{array}$ & $\begin{array}{l}\text { Standard } \\
\text { error }\end{array}$ & $\begin{array}{l}\text { Confidence } \\
\text { Interval (95\%) }\end{array}$ \\
\hline $\begin{array}{l}\text { Direct effects } \\
\text { Psychosocial }\end{array}$ & $-.101^{\mathrm{a}}$ & & \\
Factor & & & \\
Depression & $-.247^{\mathrm{b}}$ & & \\
Indirect effects & & & \\
Psychosocial & $-.069^{\mathrm{b}}$ & .022 & $-.115-.032^{\mathrm{a}}$ \\
Factor & & & \\
\hline
\end{tabular}

${ }^{a}$ Significant level at .01

${ }^{\mathrm{b}}$ Significant level at .05 depression on MSD/pain $[6,7,24,33,36]$. They agreed that the co-occurrence between MSD and depression in which individual with pain are at increased risk for depression [72, 73]. Depression is associated with pain sites, greater pain intensity, longer duration of pain, and greater likelihood of poor treatment response in those patients with pain [72]. In addition, social problems and disruption of work related with comorbid pain and depression were also reported in the literature. For example, comorbid pain and depression have reached up to $25 \%$ among patients in the Clinic of Neurology [74]. In addition, there was continuous basic of depression and pain for most of the patients after 12 months follow-up. The authors also found that baseline pain severity and the degree of depression improvement were the most influential factor in the severity of pain from time to time.

Given this, it can be suggested that depression could be one of the predictors that associated with MSD among those in the teaching profession $[6,7,12,17,33$, $35,36,75]$. However, the present study was the first study to examine this relationship specifically in Malaysia.

\section{Strengths and limitations}

The present study is one of the few studies that has examined the prevalence and predictors associated with MSD among those in the teaching profession, particularly in developing countries such as Malaysia. However, the present study also has several limitations. Firtsly, all variables were assessed using self-report measures, in which a general negativistic opinion towards the work situation and health status might have influenced the results. Also, the reports were only from the teachers' views so it may not have beeb an accurate measure of the construct.

Secondly, depression was assessed with self-report measures without any further clinical interviews or 
assessments to diagnose specific mental disorders. Lastly, the cross-sectional nature of the analyses limits the causal inferences regarding the relationship between psychosocial factors, depression and musculoskeleal disorder. However, the study findings are in line with the latest literature and suggest that the relationship between psychosocial factors, depression and MSD is robust.

\section{Conclusions}

Parallels can be drawn to the literature review: the findings from the present study support the idea that psychosocial factors and depression are significant predictors of MSD among teachers. MSD is much more disabling when depression is present because of the co-occurrence between MSD and depression in which individuals with pain are at increased risk for depression. Recommendations for future studies are based on the contributions and limitations as previously outlined. First and foremost is that longitudinal studies are necessary to be able to draw firm conclusions about the causal relationships between predictors and MSD. Such studies would enable greater exploration of the relationship between other potential predictors and MSD. Secondly, understanding this relationship is valuable and will assist teachers in in arranging, planning or actualizing preventive intervention programs in order to reduce the risk of MSD. This study also provides awareness for teachers and those parties involved such as the Malaysian Ministry of Education regarding the issues of MSD at the workplace. Currently, procedures and guidelines on good ergonomic movements for industrial workers involved with manual labor are readily available but not for teachers. Detailed and specific guidelines on good ergonomics for teachers are worth developing with the aim to minimize the prevalence and effects of MSD among teachers. Third, future intervention studies on how to reduce MSD among teachers is therefore warranted. In a nutshell, the study, within the limits posed by its cross-sectional design, supported the hypothesis that depression partially mediates the effects of psychosocial work conditions on MSD. Given this, preventive measures for MSD should also take into account these two important predictors, that is psychosocial factors and depression, in order to minimize the impact of MSD among those in the teaching profession.

\footnotetext{
Abbreviations

AMOS: Analysis moment structures; EDA: Exploratory data analysis;

EFA: Exploratory factor analysis; MSD: Musculoskeletal disorder;

SEM: Structural equation modelling; SPSS: Statistical package for social

science
}

Acknowledgements

Not applicable
Funding

Not applicable

\section{Availability of data and materials}

The datasets used and/or analysed during the current study are available from the corresponding author on reasonable request.

\section{Authors' contributions}

NYM Responsible for overall study design, data collection and analyses, interpretation of results and writing of the manuscripts (80\%). PVSK Idea on the study and conducting research and revised the manuscript (20\%). IM Idea on the study and conducting research and revised the manuscript (20\%). All authors read and approved the final manuscript.

\section{Ethics approval and consent to participate}

We were grateful that getting the ethics approval from the committee members of National University of Malaysia and the ethics approval number is NN-2017-112. We have attached with the consent to participate in the appendix as below. Written informed consent forms were given to the respondents during the data collection.

\section{Consent for publication}

Not applicable

\section{Competing interests}

The authors have no conflicts of interest to declare.

\section{Publisher's Note}

Springer Nature remains neutral with regard to jurisdictional claims in published maps and institutional affiliations.

Received: 15 August 2018 Accepted: 15 February 2019

Published online: 26 February 2019

\section{References}

1. Darwish MA, Al-Zuhair SZ. Musculoskeletal pain disorders among secondary school Saudi female teachers. Pain Res Treat. 2013;7.

2. Erick PN, Smith DR. Low back pain among school teachers in Botswana, prevalence and risk factors. BMC Musculoskelet Dis. 2014;15:359.

3. Jaafar NAT, Rahman MNA. Review on risk factors related to lower back disorders at workplace. Mater Sci Eng. 2017;226:012035.

4. Maakip I, Keggel T, Oakman J. Prevalence and predictors for musculoskeletal discomfort in Malaysian office workers: investigating explanatory factors for a developing country. Appl Ergon. 2015;53:252-7.

5. Maakip I, Keegel T, Oakman J. Predictors of musculoskeletal discomfort: a cross-culturalcomparison between Malaysian and Australian office workers. Appl Ergon. 2017;60:52-7.

6. Zamri EN, Moy FM, Hoe VCW. Association of psychological distress and work psychosocial factors with self-reported musculoskeletal pain among secondary school teachers in Malaysia. PLoS One. 2017;12:2.

7. Samad NIA, Abdullah H, Moin S, Tamrin SBM, Hashim Z. Prevalence of low back pain and its risk factors among school teachers. Am J Appl Sci. 2010; 7(5):634-9.

8. Bernal D, Campos-Serna J, Tobias A, Vargas-Prada S, Benavides FG, Serra C Work-related psychosocial risk factors and musculoskeletal disorders in hospital nurses and nursing aides: a systematic review and meta-analysis. Int J Nurs Stud. 2015:52(2):635-48.

9. Bongers PM, de Winter CR, Kompier MA, Hildebrandt VH. Psychosocial factors at work and musculoskeletal disease. Scand J Work Environment Health. 1993;19:297-312

10. Hoogendoorn WE, van Poppel MN, Bongers PM, Koes BW, Bouter LM. Systematic review of psychosocial factors at work and private life as risk factors for back pain. Spine. 2000;25:2114-25.

11. Chiu TW, Lau KT, Ho CW, Ma MC, Yeung TF, Cheung PM. A study on the prevalence of and risk factors for neck pain in secondary school teachers. Public Health. 2006;120:563-5.

12. Chiu TT, Lam PK. The prevalence of and risk factors for neck pain and upper limb pain among secondary school teachers in Hong Kong. J Occup Rehabil. 2007;17(1):19-32. 
13. Tsuboi H, Takeuchi K, Watanabe M, Hori R, Kobayashi F. Psychosocial factors related to low back pain among school personnel in Nagoya, Japan. Ind Health. 2002;40:266-71.

14. Mohseni-Bandpei MA, Ehsani F, Behtash H, Ghanipour M. Occupational low back pain in primary and high school teachers: prevalence and associated factors. J Manip Physiol Ther. 2014;37:702-8.

15. Yue PY, Liu FY, Li LP. Neck/shoulder pain and low back pain among school teachers in China, prevalence and risk factors. BMC Public Health. 2012;12:789.

16. Bongers $P$, ljmker $S$, van den Heuvel $S$, Blatter B. Epidemiology of workrelated neck and upper limb problems: psychosocial and personal risk factors (part I) and effective interventions from a bio behavioural perspective (part II). J Occup Rehabil. 2006;16(3):279-302.

17. Cardoso JP, Ribeiro IDQB, Araújo TM, Carvalho FM, Reis EJFB. Prevalence of musculoskeletal pain among teachers. Brazilian J Epidemiol. 2009;12:1-10.

18. Eatough EM, Way JD, Chang $\mathrm{CH}$. Understanding the link between psychosocial work stressors and work-related musculoskeletal complaints. Appl Ergon. 2012;43(3):554-63.

19. Clairborne N, Vandenburgh $H$, Krause TM, Leung P. Measuring quality of life changes in individuals with chronic low back pain conditions: a back education programme evaluation. Eval Programme Plann. 2002;25:61-70.

20. WHO. Depression and other common mental disorders global health estimates. Geneva: WHO Document Production Services; 2017.

21. National Institute of Mental Health (2011) Depression, 2011. Retrieved from https://www.nimh.nih.gov/health/publications/depression/depressionbooklet_34625.pdf.

22. Vietri J, Otsubo T, Montgomery W, Tsuji T, Harada E. The incremental burden of pain in patients with depression: results of a Japanese survey. BMC Psychiatry. 2015;15(1):104.

23. Banks SM, Kerns RD. Explaining high rates of depression in chronic pain: a diathesis-stress framework. Psychol Bull. 1996;119(1):95-110.

24. Poleshuck EL, Bair MJ, Kroenke K, Damush TM, Wamzhu T, Jingwei W, Krebs EE, Giles DE. Psychosocial stress and anxiety in musculoskeletal pain patients with and without depression. Gen Hosp Psychiatry. 2009;31:116-22.

25. Labour Force Survey. Work related Musculoskeletal disorder (WRMSD) Statistics, Great Britain. 2016. http://www.hse.gov.uk/statistics/index.htm. Accessed 8 Apr 2018.

26. Durmus D, IIlhanili I. Are there work-related musculoskeletal problems among teachers in Samsun, Turkey? J Back Musculoskelet Rehabil. 2012;25(1):5-12

27. Korkmaz NC, Cavlak U, Telci EA. Musculoskeletal pain, associated risk factors and coping strategies in school teachers. Sci Res Essays. 2001;6(3):649-57.

28. Allsop L, Ackland T. The prevalence of playing-related musculoskeletal disorders in relation to piano players' playing techniques and practicing strategies. Music Perform Ance Res. 2010;3(1):61-78.

29. Chong $\mathrm{EY}, \mathrm{Chan} \mathrm{AH}$. Subjective health complaints of teachers from primary and secondary schools in Hong Kong. Int J Occup Saf Ergon. 2010;16:23-39.

30. International Labour Office (ILO). Standards on occupational safety and health: promoting a safe and healthy working environment. Geneva: International Labour Office; 2009.

31. Tessa. Is teaching bad for your back? Teaching expertise. 2010 http://www. teachingexpertise.com/articles/teaching-bad-back-598. Accessed 10 Apr 2018

32. Anuar NFM, Rasdi I, Saliluddin SM, Abidin EZ. Work task job satisfaction predicting low Back pain among secondary school teachers in Putrajaya. Iran J Public Health. 2016:43(1):85-92.

33. Balakrishnan R, Chellappan ME, Thenmozhi. Prevalence of low back pain and its risk factors among secondary school teachers at bentong, Pahang. Int J Phys Educ Sports Health. 2016;3(2):35-40.

34. McKeon M, Albert WJ, Neary JP. Assessment of neuromuscular and hemodynamic activity in individuals with and without chronic low back pain. Dyn Med. 2006;5:6.

35. Tavafian SS, Jamshidi A, Mohammad K, Montazeri A. Low back pain education and short term quality of life: a randomized trial. BMC Musculoskelet Disord. 2007:8:21.

36. Rahimi A, Vazini H, Alhani F, Anoosheh M. Relationship between low Back pain with quality of life, Depression, anxiety and stress among emergency medical technicians. Trauma Mon. 2015;20(2).

37. Kidger J, Brockman R, Tilling K, Campbell R, Ford T, Araya R, Gunnell D. Teachers' wellbeing and depressive symptoms, and associated risk factors: a large cross sectional study in English secondary schools. J Affect Disord. 2016;192:76-82.

38. Mukundan J, Khandehroo K. Burnout in relation to gender, educational attainment and experience among Malaysian ELT practitioner. J Hum Res Adult Learn. 2009;5(2):93-8.
39. Ceballos AGdCd, Santos GB. Factors associated with musculoskeletal pain among teachers: socio demographics aspects, general health and wellbeing at work. Rev Bras Epidemiol. 2015;18(3):702-15.

40. Ilgan A, Ozu-Cengiz O, Ata A, Akram A. The relationship between teachers' psychological well-being and their quality of school work life. J Happiness Well Being. 2015;3:159-81.

41. Health and Safety Executive. Work Related Musculoskeletal Disorder (WRMSDs) Statistics, Great Britain 2016. United Kingdom: Health and Safety Executive; 2016. http://www.hse.gov.uk/statistics/overall/hssh1516.pdf?pdf= hssh1516. Accessed 20 Apr 2018

42. Minister of Employment and Labor. Industrial Disaster in Korea. Sejong: Minister of Employment and Labor; 2017.

43. Morken T, Riise T, Moen B, Hauge SHV, Holien S, Langedrag A, Pedersen S, Saue ILL, Seljebø GM, Thoppil V. Low back pain and widespread pain predict sickness absence among industrial workers. BMC Musculoskeletal Disorder. 2003;4:21.

44. Annual report of Malaysia Social Security Organization (SOCSO) 1995-2009. Retrieved from https://www.perkeso.gov.my/images/laporan_tahunan/ Laporan_Tahunan_2015.pdf.

45. Bhattavharya A. Cost of occupational musculoskeletal disorders (MSDs) in the United States. Int J Ind Ergon. 2014;44(3):448-54.

46. Piedrahita $H$, Punnett L, Shahnavaz H. Musculoskeletal symptoms in cold exposed and noncold exposed workers. Int J Ind Ergon. 2004;34:271-8.

47. Carayon P, Smith MJ, Haims MC. Work organization, job stress, and workrelated musculoskeletal disorders. Hum Factors. 1999;41(4):644-63.

48. Devereux JJ, Buckle PW, Vlachonikolis IG. Interactions between physical and psychosocial work risk factors increase the risk of back disorders: an epidemiological study. Occup Environ Med. 1999;56:343-53.

49. Sauter SL, Swanson NG. An ecological model of musculoskeletal disorders in office work. In: Sauter SL, Moon SD, editors. Beyond biomechanics: psychosocial aspects of musculoskeletal disorders in office work. Bristol; 1996. p. 3-20.

50. Armstrong TJ, Buckle P, Finem LJ, Hagberg M, Jonsson B, Kilbom $\AA$ Kuorinka I, Silverstein BA, Sjøgaard G, Viikari-Juntura E. A conceptual model for work-related neck and upper-limb musculoskeletal disorders. Scand J Work Environ Health. 1993;19:73-84.

51. Kumar S. Theories of musculoskeletal injury causation. Ergonomics. 2001; 44(1):17-47

52. Kjellberg A, Wadman C. The role of the affective stress response as a mediator of the effect of psychosocial risk factors on musculoskeletal complaints_-part 1: assembly workers. Int J Ind Ergon. 2007;37:367-74.

53. Davis KG, Heaney CA. The relationship between psychosocial work characteristics and low back pain: underlying methodological issues. Clin Biomech. 2000;15:389-406.

54. Karsh BT. Theories of work related musculoskeletal disorders: implications for ergonomic inventions. Theor Issues Ergon Sci. 2006;7(1):71-88.

55. Hartvigsen J, Lings S, Leboeuf-Yde C, Bakketeig L. Psychosocial factors at work in relation to low back pain and consequences of low back pain; a systematic, critical review of prospective cohort studies. Occup Environ Med. 2014;61:e2.

56. The Malaysian Insider Team. When even RM12, 000 a month isn't enough to get by in Malaysia. 2013. http://www.themalaysianinsider.com/malaysia/ article/when-even-rm12000-a-month-isnt-enough-to-get-by-in-malaysia. Accessed 20 Apr 2018.

57. Griffiths A, Cox T, Karanika M, Khan S, Tomas J. Work design and management in the manufacturing sector: development and validation of the work organisation assessment questionnaire. Occup Environ Med. 2006;63(10):669-75.

58. Mukhtar F, Oei TPS. Exploratory and confirmatory factor validation and psychometric properties of the Beck Depression inventory for Malays (BDIMalay) in Malaysia. Malays J Psychiatry. 2008;17:1.

59. Oakman J, Macdonald W, Wells Y. Developing a comprehensive approach to risk management of musculoskeletal disorders in non-nursing health care sector employees. Appl Ergon. 2014;45(6):1634-40.

60. Maakip I, Ng YM, Voo PSK. Kecelaruan muskuloskeletal dalam kalangan jururawat: Satu Kajian di Hospital Kuala Lumpur. Jurnal Psikologi dan Perkhidmatan Awam Malaysia. 2014;9:1-20.

61. Pallant J. SPSS: Survival Manual. 4th ed. Berkshire: Open University Press; 2010.

62. Hair JF, Black WC, Babin BJ, Anderson RE. Multivariate data analysis. 7th ed. United States of America: Pearson Prentice Hall; 2010.

63. Baron R, Kenny DA. The moderator-mediator variable distinction in social psychological research: conceptual, strategic, and statistical considerations. J Pers Soc Psychol. 1986;51(6):1173-82. 
64. James LR, Brett JM. Mediators, moderators and tests for mediation. J Appl Psychol. 1984;69:307-21.

65. Hu LT, Bentler PM. Cut-off criteria for fit indexes in covariance structure analysis: conventional criteria versus new alternatives. Struct Equ Model. 1999;6:1-55.

66. Fjellman -Wiklund A, Brulin C, Sundelin G. Physical and psychosocial workrelated risk factors associated with neck-shoulder discomfort in male and female music teachers. Med Prob Perf Art. 2003;18(1):33-41.

67. Smedley J, Inskip H, Trevelyan F, Buckle P, Cooper C, Coggon D. Risk factors for incident neck and shoulder pain in hospital nurses. Occup Environ Med. 2003;60:864-9.

68. Gureje O, Simon GE, Von Korff M. A cross-national study of the course of persistent pain in primary care. Pain. 2001;92:195-200.

69. Wademan C, Kjellberg A. The role of the affective stress response as a mediator for the effect of psychosocial risk factors on musculoskeletal complaints- part 2: hospital workers. Int J Ind Ergon. 2007;37:395-403.

70. Ji HB, Young SK, Kwan HY. Relationship between comorbid health problems and musculoskeletal disorders resulting in musculoskeletal complaints and musculoskeletal sickness absence among employees in Korea. Saf Health Work. 2015;6(2):128-33.

71. Dersh J, Gatchel RJ, Polatin P, Mayar T. Prevalence of psychiatric disorders in patients with chronic work-related musculoskeletal pain disability. J Occup Environ Med. 2002;44:459-68.

72. Bair MJ, Robinson RL, Katon W, Kroenke K. Depression and pain comorbidity: a literature review. Arch Intern Med. 2008;63:2433-45.

73. Gallagher RM, Verma S. Managing pain and comorbid depression: a public health challenge. Semin Clin Neuropsychiatry. 1999;4:203-20.

74. Williams LS, Jones WJ, Shen J, Robinson RL, Weinberger M, Kroenke K. Prevalence and impact of depression and pain in neurology outpatients. J Neurol Neurosurg Psychiatry. 2003;74:1587-9.

75. Smith DR, Mihashi M, Adachi Y, Koga $H$, Ishitake T. A detailed analysis of musculoskeletal disorders among Japanese nurses. J Safe Res. 2006;37:195-200.

Ready to submit your research? Choose BMC and benefit from:

- fast, convenient online submission

- thorough peer review by experienced researchers in your field

- rapid publication on acceptance

- support for research data, including large and complex data types

- gold Open Access which fosters wider collaboration and increased citations

- maximum visibility for your research: over $100 \mathrm{M}$ website views per year

At BMC, research is always in progress.

Learn more biomedcentral.com/submissions 